Orijinal Araștırma

\title{
Tip 2 diyabetli hastalarda mukokutanöz fungal infeksiyonlar için risk faktörleri
}

\author{
Risk factors for mucocutaneous fungal infections in patients with \\ type 2 diabetes mellitus
}

\section{Düriye Deniz Demirseren, Gülșen Akoğlu, Selma Emre, Ahmet Metin, Fatma Neslihan Çuhadar*, Bekir Çakır*}

Ankara Atatürk Araștırma ve Eğitim Hastanesi, Dermatoloji, *Endokrinoloji Kliniği, Ankara, Türkiye

\section{Özet}

Amaç: Diyabetes mellituslu (DM) hastalarda mukokutanöz fungal infeksiyonlar sık görülmektedir. Ancak diyabeti olan her hastada fungal infeksiyonlara rastlanmamaktadır. Bu çalışmada Tip 2 DM olan hastalarda görülen mukokutanöz fungal infeksiyonlarının araştıııması ve Tip 2 DM hastalarında fungal infeksiyonlar için risk faktörlerininin belirlenmesi amaçlanmıştır.

Gereç ve Yöntem: Çalışmaya mukokutanöz fungal infeksiyonu olan 302 Tip 2 DM hastası ve mukokutanöz fungal infeksiyonu olmayan 326 Tip 2 DM hastası dahil edildi. Hastaların demografik ve klinik özellikleri, HbA1c düzeyleri, DM süreleri, vücut kitle indeksleri (VKi) ve DM ilişkili komplikasyonları karşılaştııılı ve fungal infeksiyonların gelişmesi için risk faktörleri belirlendi.

Bulgular: Mukokutanöz mantar hastalığı olan 302 hastanın \%81,2'sinde $(n=245)$ dermatofit infeksiyonu, \%16,9'unda ( $n=51)$ kandidal infeksiyon, \%2,0'ında $(n=6)$ pitriyasis versikolor infeksiyonu saptandı. Fungal infeksiyonu olan diyabetik hastalarda erkek cinsiyet, yaş, diyabet süresi, diyabetik nefropati, nöropati ve retinopati varlı̆ı fungal infeksiyonu olmayan diyabetik hastalara göre anlamlı olarak daha fazla idi (hepsi için $p<0,05)$. Erkek cinsiyet, 50 yaş ve üzerinde olmak, nefropati ve nöropatinin eşlik etmesi Tip 2 DM olan hastalarda mukokutanöz fungal infeksiyon gelişmesi için bağımsız risk faktörleri olarak belirlendi. Alt grup analizleri yapıldığında ise dermatofit infeksiyonları için erkek cinsiyet, 50 yaş üzeri olmak, diyabet süresinin beş yıl ve üzerinde olması ile nefropati olması; kandidal infeksiyonlar için ise vücut kitle indeksinin 30 ve üzeri olması ve nöropati bulunması bağımsız risk faktörleri olarak saptandı.

Sonuç: illeri yaş, erkek cinsiyet, diyabetik nöropati ve nefropati varlığı Tip 2 DM tanısı olan hastalarda mukokutanöz fungal infeksiyonların gelişimi ile yakından ilişkilidir. (Türkderm 2014; 48: 87-91)

Anahtar Kelimeler: Diyabetes mellitus, fungal infeksiyon, risk faktörleri

\section{Summary}

Background and Design: Mucocutaneous fungal infections are common in patients with diabetes mellitus (DM). However, fungal infections do not develop in all patients with DM. In this study, we aimed to determine the risk factors for mucocutaneous fungal infections in patients with Type 2 DM.

Materials and Methods: A total of 302 Type 2 DM patients with mucocutaneous fungal infections and 326 Type 2 DM patients without mucocutaneous fungal infections were enrolled. Demographic and clinical features, HbA1c levels, DM durations, body mass indexes (BMIs) and DM-related complications were compared between the groups and risk factors for developing mucocutaneous fungal infections were determined.

Results: Of the 302 patients with mucocutaneous fungal infections, $81.2 \%(n=245)$ had dermatophytosis, $16.9 \%(n=51)$ had candida infections, and $2.0 \%(n=6)$ had pityriasis versicolor. Frequency of male gender, diabetic nephropathy, neuropathy and retinopathy; DM durations and age of patients were all significantly higher in diabetic patients with fungal infections than in patients without fungal infections (all $p<0.05)$. Male gender, age $\geq 50$ years, nephropathy and neuropathy were independently associated with fungal infection in Type 2 DM patients. In subgroup analyses, independent risk factors for dermatophytosis were male gender, age $\geq 50$ years, DM duration $\geq 5$ years, and nephropathy. For candidiasis, these factors were $\mathrm{BMI} \geq 30$ and neuropathy.

Conclusion: Elderly, male gender, diabetic neuropathy and nephropathy are closely associated with mucocutaneous infections in patients with Type 2 DM. (Turkderm 2014; 48: 87-91)

Key Words: Diabetes mellitus, fungal infection, risk factors

Yazışma Adresi/Address for Correspondence: Dr. Düriye Deniz Demirseren, Ankara Atatürk Araştırma ve Eğitim Hastanesi, Dermatoloji Kliniği, Ankara, Türkiye Tel.: +90 31229125 25/4120 E-posta: ddemirseren@yahoo.com Geliş Tarihi/Received: 21.03.2013 Kabul Tarihi/Accepted: 03.06.2013

Türkderm-Deri Hastalıkları ve Frengi Arșivi Dergisi, Galenos Yayınevi tarafından basılmıștır.

Turkderm-Archives of the Turkish Dermatology and Venerology, published by Galenos Publishing. 


\section{Giriş}

Diyabetes mellitus (DM) tüm dünyada en sık görülen endokrin ve metabolizma hastalığı olup prevalansı \%7,2'dir. Tip 2 DM tüm diyabet hastalarının \%90'dan fazlasını oluşturmaktadır1,2. Tip 2 DM'te deri infeksiyonlarının daha sık olduğu bilinmektedir. Kötü metabolik kontrol ve yüksek hemoglobin $\mathrm{A} 1 \mathrm{c}(\mathrm{HbA} 1 \mathrm{C})$ düzeylerinin bu duruma neden olduğu öne sürülmektedir2.

Mukokutanöz fungal infeksiyonlar diyabetli hastalarda saptanan deri infeksiyonları arasında en sık rastlananlardır2-5. Fungal infeksiyonların DM hastalarının \%10-\%60'ında bulunduğu bildirilmiştir3,4. Ülkemizde diyabet hastalarında dermatolojik hastalıkları araştıran çalışmalar yapılmıştır3-6. Fakat bizim bilgilerimize göre ülkemizde DM hastalarında mukokutanöz mantar infeksiyonları için risk faktörlerini inceleyen bir çalışma bulunmamaktadır. Bu çalışma ile Tip 2 DM'li hastalardaki mukokutanöz mantar hastalıklarının sıklığını, cinsiyetlere göre dağılımını, hastaların yaş, HbA1C değerleri, hastalık süreleri, vücut kitle indeksleri (VKi) ve diyabetin diğer komplikasyonları ile ilişkisinin incelenmesi ve Tip 2 diyabetli hastalardaki bağımsız risk faktörlerininin belirlenmesi amaçlanmıştır.

\section{Gereç ve Yöntem}

Çalışmaya hastanemiz endokrinoloji ve metabolizma hastalıkları kliniği tarafından Tip 2 diyabet tanısıyla izlenen yaşları 22 ile 87 arasında değişen 350'si kadın, 276'sı erkek toplam 628 hasta dahil edildi. Hastaların hepsinin genel dermatolojik muayeneleri yapıldı ve 302'sinde mukokutanöz fungal infeksiyon tespit edildi. Diğer 326 Tip 2 DM hastasında ise fungal veya herhangi bir infeksiyon saptanmadı. Fungal infeksiyon tanısı ve tiplendirmesi dermatoloji uzmanları tarafından klinik olarak ve direkt mikroskopik inceleme ile doğrulanarak yapıldı. Fungal infeksiyonu saptanan hastaların infeksiyon bölgeleri ve klinik özellikleri kayıt edildi. Hastalar dermatofit infeksiyonları, kandidal infeksiyonlar ve pitriyasis versikolor infeksiyonları olarak üç ana gruba ayrıldı. Hastaların demografik bilgileri, diyabet süreleri, VKi'leri, HbA1C değerleri ve eşlik eden nefropati, retinopati veya nöropati komplikasyonları kayıt edildi. Idrarda $30 \mathrm{mg}$ üstünde mikroalbümünürisi olan hastalar nefropati kabul edildi?. Hastaların VKi'leri vücut ağırlığı $(\mathrm{kg}) /$ boy $(\mathrm{m})^{2}$ formülü ile hesaplandı. HbA1C değerleri $8 \mathrm{mmol}$ $\mathrm{mL}$ ve üzerinde olan hastalar diyabeti regüle olmayan hastalar olarak kabul edildi8. Hastalar cinsiyetlerine göre, 50 yaş altı ve üstü, diyabet süreleri beş yıl altı ve üstü, VKi'leri 30'un altı ve üstü, HbA1C değerleri $8 \mathrm{mmol} / \mathrm{mL}$ altı ve üstü olarak gruplandırıldı. Fungal, dermatofit, kandida infeksiyonu ve onikomikozu olan ve olmayan hastalar klinik özellikleri açısından ayrı ayrı karşılaştırılarak bu infeksiyonlar için risk faktörleri belirlendi.

Çalışmaya katılan hastalar çalışma konusunda aydınlatılıp, bilgilendirilmiş onay formları imzalatıldı. Araştırma için hastanemiz etik kurulundan onay alındı.

Elde edilen verilerin istatistik analizi SPSS 16.0 programı ile yapıldı. Kategorik değişkenlerin karşılaştııımasında çapraz tablo istatistikleri kullanıldı (Ki-kare testi). P değerinin <0,05 olması anlamlı kabul edildi. Bağımsız risk faktörlerinin belirlenmesinde çok değişkenli varyant analizi kullanıldı.

\section{Bulgular}

Tip 2 diyabetli hastaların 350'si kadın 276'sı erkek, yaş ortalamaları $57,01 \pm 10,44$ idi. Hastaların VKi ortalama $31,47 \pm 5,68$, diyabet süreleri 1-40 yıl arasında değişmekte olup ortalama 8,65 $\pm 7,34$ yı idi. HbA1C değerleri 5-16 $(7,77 \pm 1,76) \mathrm{mmol} / \mathrm{mL}$ idi. Hastaların \%38,7'sinde nöropati, $\% 23,9$ 'unda nefropati ve \%23,3 'ünde retinopati mevcuttu (Tablo 1). Mukokutanöz fungal infeksiyonu olan 302 hastanın 245'inde $(\% 81,1)$ dermatofit infeksiyonu, 51'inde (\%16,8) kandidal infeksiyon, altısında $(\% 2,00)$ pitriasis versikolor mevcuttu (Tablo 2). Fungal infeksiyonu olan ve olmayan hastalar karşılaştırıldığında fungal infeksiyonları olan grupta erkek cinsiyet, yaş, diyabet süresi, nefropati, nöropati ve retinopati varlığ fungal infeksiyonu olmayan gruptan anlamlı olarak daha fazla idi (hepsi için $p<0,05)$ (Tablo 3). Çok değişkenli varyant analiz yapıldığında erkek cinsiyet, 50 yaş ve üzerinde olmak, nefropati ve nöropatinin eşlik etmesi Tip 2 DM olan hastalarda mukokutanöz fungal infeksiyon gelişmesi için bağımsız risk faktörleri olarak belirlendi (Tablo 4).

\begin{tabular}{|c|c|}
\hline Özellik & \\
\hline $\begin{array}{l}\text { Yaş (min-max) } \\
\text { (ortalama } \pm \text { SD) }\end{array}$ & $\begin{array}{l}22-87 \\
57,01 \pm 10,44\end{array}$ \\
\hline $\begin{array}{l}\text { Cinsiyet (n (\%) } \\
\text { Erkek } \\
\text { Kadın }\end{array}$ & $\begin{array}{l}350(55,9) \\
276(44,1)\end{array}$ \\
\hline $\begin{array}{l}\text { DM süresi (yıl) (min- max) } \\
\text { (ortalama } \pm \text { SD) }\end{array}$ & $\begin{array}{l}1-40 \\
8,65 \pm 7,34\end{array}$ \\
\hline $\begin{array}{l}\text { HbA1c düzeyi }(\mathrm{mmol} / \mathrm{mL} \text { ) (min- max) } \\
\text { (ortalama } \pm \mathrm{SD} \text { ) }\end{array}$ & $\begin{array}{l}5-16 \\
7,77 \pm 1,76\end{array}$ \\
\hline $\begin{array}{l}\text { VKi (min-max) } \\
\text { (ortalama } \pm \text { sd) }\end{array}$ & $\begin{array}{l}17-53 \\
31,47 \pm 5,68\end{array}$ \\
\hline Nefropati varlığı n (\%) & $242(38,7)$ \\
\hline Nöropati varlığı n (\%) & $149(23,9)$ \\
\hline Retinopati varlığı n (\%) & $145(23,3)$ \\
\hline
\end{tabular}

Tablo 2. Mukokutanöz fungal infeksiyonu olan 302 hastanın klinik özellikleri

\begin{tabular}{|l|l|l|}
\hline & $\mathbf{n}$ & $\%$ \\
\hline Dermatofit infeksiyonu & 245 & 81,1 \\
\hline Tinea pedis & 82 & 27,1 \\
\hline Onikomikoz & 72 & 23,8 \\
\hline Birden fazla dermatoifit infeksiyonu & 112 & 37,0 \\
\hline Tinea korporis & 2 & 0,7 \\
\hline Kandidal infeksiyonu & 51 & 16,9 \\
\hline Oral mukoza & 11 & 3,6 \\
\hline Genital mukoza & 9 & 3,0 \\
\hline Intertriginöz tip & 28 & 9,3 \\
\hline Kandidal onikomikoz & 3 & 1,0 \\
\hline Tinea versikolor & 6 & 2,00 \\
\hline
\end{tabular}




\section{Tablo 3. Fungal infeksiyonu olan diyabetes mellitus'lu hastalar ile fungal infeksiyonu olmayan DM'li hastaların} demografik ve klinik özelliklerinin karşılaştırılması

\begin{tabular}{|c|c|c|c|}
\hline & $\begin{array}{l}\text { Fungal infeksiyonu olan } \\
\text { DM hastalar }(n=302)\end{array}$ & $\begin{array}{l}\text { Fungal infeksiyonu olmayan DM } \\
\text { hastalar }(n=326)\end{array}$ & $\mathbf{p}$ \\
\hline Yaş (yıl) ortalama \pm SD (aralık) & $59,10 \pm 9,61$ & $55,04 \pm 10,82$ & $<0,001$ \\
\hline Erkek cinsiyet; $n(\%)$ & $155(\% 56,2)$ & $121(\% 43,8)$ & $<0,001$ \\
\hline DM süresi (yıl) ortalama \pm SD (aralık) & $99,55 \pm 7,83(1-40)$ & $7,81 \pm 6,76(1-35)$ & 0,003 \\
\hline HbA1c düzeyi, (mmol/mL) ortalama $\pm S D$ (aralık) & $7,88 \pm 1,74(5-14)$ & $7,67 \pm 1,77(5-16)$ & 0,120 \\
\hline Nöropati varlığı; n (\%) & $133(44,2)$ & $109(33,6)$ & 0,011 \\
\hline Retinopati varlığı; n (\%) & $82(27,3)$ & $63(19,5)$ & 0,008 \\
\hline
\end{tabular}

Dermatofit infeksiyonları olan ve olmayan hastalar karşılaştııılığında diyabet süresi, erkek cinsiyet, yaş, nefropati, nöropati ve retinopati varlığı dermatofit infeksiyonu olanlarda anlamlı olarak fazla bulundu (hepsi için $p<0,05$ ). Dermatofit infeksiyonları için erkek cinsiyet, 50 yaş üzeri olmak, nefropati varlığı ve diyabet süresinin beş yıl ve üzerinde olması bağımsız risk faktörleri olarak saptandı (Tablo 5).

Kandidal infeksiyonları olan ve olmayan hastalar karşılaştııılığında, diyabet süresi HbA1C düzeyleri, VKI, nefropati, nöropati ve retinopati varlığı kandidal infeksiyonu olan hastalarda anlamlı olarak fazla bulundu $(p<0,05)$. Kandidal infeksiyonlar için VKi'nin 30 ve üzeri olması ve nöropati bulunması bağımsız risk faktörleri olarak tespit edildi (Tablo 6). Onikomikozu olan hastalarda erkek cinsiyet, yaş, diyabet süresi, nefropati, nöropati ve retinopati varlığı onikomikozu olmayan hastalardan anlamlı olarak fazla idi (hepsi için $p<0,005$ ). Onikomikoz için bağımsız risk faktörleri ise erkek cinsiyet, 50 yaş üstü ve nöropati bulunması olarak bulundu (Tablo 7).

\section{Tartışma}

Diyabet her yaş ve sosyoekonomik gruptaki bireyleri etkileyebilen ve yaygınlığı giderek artan bir metabolizma hastalığıdır9. Diyabet hastalarında tüm sistemleri içeren komplikasyonlar gözlenebilir. Nöropati, nefropati, retinopati ve kardiovasküler sistem hastalıkları gibi komplikasyonların yanı sıra dermatolojik komplikasyonlar da sık görülür. Diyabet hastalarında görülen infeksiyonlar, diyabete özgü bulgular olmasa da diyabetli hastalarda mukokutanöz infeksiyonların görülme sıklığı artmıştır6,10. DM'de bu infeksiyonların sık görülmesinin nedeni kötü mikrosirkülasyon, fagositik aktivitenin azalması ve gecikmiş kemotaksistir2

Çalışmamızda Tip 2 diyabet hastalarında çeşitli fungal infeksiyonlar saptanmıştır. Sıklık açısından saptadığımız en sık fungal infeksiyon tinea pedis iken ikinci sırayı onikomikoz alıyordu. Bu sonuç diğer araştırmaların sonuçlarıyla uyumlu bulunmakla birlikte6,11,12, bazı araştırmalarda ilk sırayı onikomikoz almaktadır ${ }^{3}$. Hastalarımız arasında birden fazla fungal infeksiyonu olan hastaların oranı da oldukça yüksekti ve en sık birliktelik gösteren iki infeksiyon tinea pedis ve onikomikoz idi $(\% 98,2)$. Bulaşın kolay olması nedeniyle bu iki infeksiyonun sık birliktelik gösterdiği düşünülmüştür.

Sadece dermatofit infeksiyonları değerlendirildiğinde erkek cinsiyet, ileri yaş ve nefropatinin yanı sıra diyabet süresinin beş yıldan uzun olması da risk faktörü olarak bulundu. Hastalık süresi arttıkça hem komplikasyon

Tablo 4. Diyabetes mellitus hastalarında mukokutanöz
fungal infeksiyonlar için bağımsız risk faktörleri
\begin{tabular}{|l|l|l|}
\hline Mantar & p değeri & Risk oranı (\%95 güven aralığı) \\
\hline Yaş & $<0,001$ & $1,037(1,019-1,0559$ \\
\hline Cinsiyet & $<0,001$ & $1,884(1,333-2,664)$ \\
\hline Nefropati & $<0,001$ & $1,632(1,083-2,459)$ \\
\hline Nöropati & 0,011 & $1,372(0,948-1,985)$ \\
\hline
\end{tabular}

Tablo 5. Diyabetes mellitus hastalarında dermatofit, kandida ve onikomikoz infeksiyonu için bağımsız risk faktörleri

\begin{tabular}{|l|l|l|}
\hline Dermatofit & p değeri & Risk oranı $(\%$ 95 güven aralığı) \\
\hline Yaş & $<0,001$ & $2,242(1,472-3,343)$ \\
\hline Cinsiyet & $<0,001$ & $2,157(1,509-3,084)$ \\
\hline Nefropati & $<0,001$ & $1,797(1,179-2,738)$ \\
\hline Nöropati & 0,011 & $1,435(0,981-2,089)$ \\
\hline Kandida \\
\hline VKi & 0,005 & $1,898(1,026-3,890)$ \\
\hline Nöropati & 0,012 & $2,086(1,045-3,767)$ \\
\hline Onikomikoz & $p<0,001$ & $2,846(1,691-4,791)$ \\
\hline Yaş & $p<0,001$ & $2,476(1,645-3,726)$ \\
\hline Cinsiyet & 0,002 & $2,476(1,645-3,726)$ \\
\hline Nöropati
\end{tabular}

Tablo 6. Diyabetes mellitus hastalarında mukokutanöz kandida infeksiyonu için bağımsız risk faktörleri

\begin{tabular}{|l|l|l|}
\hline Kandida & p değeri & Risk oranı (\%95 güven aralığı) \\
\hline VKi & 0,005 & $1,898(1,026-3,890)$ \\
\hline Nöropati & 0,012 & $2,086(1,045-3,767)$ \\
\hline
\end{tabular}

Tablo 7. Diyabetes mellitus hastalarında onikomikoz infeksiyonu için bağımsız risk faktörleri

\begin{tabular}{|l|l|l|}
\hline Onikomikoz & p değeri & Risk oranı (\%95 güven aralığı) \\
\hline Yaş & $p<0,001$ & $2,846(1,691-4,791)$ \\
\hline Cinsiyet & $p<0,001$ & $2,476(1,645-3,726)$ \\
\hline Nöropati & 0,002 & $2,016(1,332-3,051)$ \\
\hline
\end{tabular}


gelişme riski artmakta hem de infeksiyonlara karşı direnç zayıflamaktadır Bu nedenle diyabetli hastalarda görülen en sık infeksiyon grubu olan dermatofit infeksiyonları da artmaktadır. Shahzad ve ark. ${ }^{11}$ mantar infeksiyonlarını diyabet süresiyle ilişkili bulmuşlardır. Buna karşılık Romano ve ark. ${ }^{12}$ dermatofit infeksiyonları ile diyabet süresi, $\mathrm{HbA} 1 \mathrm{c}$ seviyesi ve glukoz seviyeleri ile ilişkili olmadığını bildirmişlerdir. Bizim çalışmamızda da Romano ve ark.'nın çalışmasına benzer şekilde HbA1c seviyeleri ile dermotofit infeksiyonları arasında bir ilişki bulunmamıştır.

Diyabet hastalığı aynı zamanda kandidal infeksiyonlara predispozisyon yaratan faktörlerden biridir ve sık kandida infeksiyonları diyabetin erken habercisi olabilmektedir. DM'li hastalarda oral, genital ve intertriginöz kandidiazise diyabeti olmayanlara göre daha sık rastlanır ${ }^{13-15}$. Bu çalışmada kandidal infeksiyonlu hastalarda diyabet süresi, $\mathrm{HbA} 1 \mathrm{C}$ düzeyleri, vücut kitle indeksi, nefropati, nöropati ve retinopati kandida infeksiyonu olmayan hastalardan anlamlı olarak fazla idi. Al-Attas ve ark. ${ }^{16}$ Tip 2 diyabet hastalarında glisemik kontrol bozukluğu ile oral kandida infeksiyonu arasında yakın ilişkili bulmuşlardır. Bu sonuçlar bizim sonuçlarımız ile benzerdir. Çalışmamızda kandida infeksiyonu olan hastalarda $\mathrm{HbA} 1 \mathrm{c}$ düzeyleri kandida infeksiyonu olmayanlardan anlamlı olarak yüksek bulunmuştur. Fakat kandidası olanlar dışında hastalarımızda fungal infeksiyonu olanlar ve olmayanlar arasında HbA1c düzeyleri yönünden anlamlı fark yoktu. Şensoy ve ark. ${ }^{3}$ uzun süreli kontrolsüz hipergliseminin bir göstergesi olan $\mathrm{HbA} 1 \mathrm{c}$ düzeyleri ile kutanöz fungal infeksiyonlar arasında korelasyon olmadığını bildirdiler. Hekimsoy ve ark. ${ }^{5}$ da benzer şekilde $\mathrm{HbA} 1 \mathrm{c}$ düzeyleri ile fungal infeksiyonlar arasında ilişki olmadığını gözlemlediler. Bu sonuçlara göre glisemik kontrolün iyi olmadığı diyabet hastalarında artan tek fungal infeksiyon grubunun mukokutanöz kandida infeksiyonları olduğu görülmektedir.

Ancak çalışmamızda yapılan ileri analizlerde kandidal infeksiyonlar için VKi'nin 30'un üstünde olması ve nöropatinin bulunması bağımsız risk faktörü olarak bulunmuş, HbA1c düzeyleri bu sonuçlarda risk faktörü olarak saptanmamıştır. Bu durum $\mathrm{HbA} 1 \mathrm{c}$ değerlerinin dolaylı olarak etkili olduğunu düşündürmüştür. Kandida infeksiyonlarının obez hastalarda fazla olması intertriginöz alanların bu kişilerde daha geniş olmasına bağlanabilir. Nöropati bulunması da yine uzun süreli kontrolsüz diyabeti işaret ettiğinden bu hastalarda kandidal infeksiyonların artışın açıklayabilir.

Diyabetli hastalardaki mantar infeksiyonları ile ilgili araştırmaların çoğu onikomikoz üzerine yoğunlaşmıştır7,9,12,17,18. Diyabetik ayak gelişimi, selülit, osteomyelit, tromboflebit infeksiyonu gelişimi gibi ciddi komplikasyonlara yol açabileceğinden ayak bölgesi infeksiyonları diyabetli hastalarda çok önemlidir9,10. Kronik erozyon ve ülserler bakteri ve fungal infeksiyon girişine yol açarak gecikmiş yara iyileşmesi ile birlikte artmış morbiditeye ve alt ekstremite amputasyonlarına gidebilecek sonuçlara yol açabilir. Ayrıca hastalarda periferal arter hastalığı bulunması, nöropatinin olması ve uygunsuz ayakkabı giyimi gibi faktörlerin varlığı da potansiyel ciddi sonuçları arttıran faktörlerdir 18,19 . Önceki çalışmalarda; erkek cinsiyet, ileri yaş, obezite, HbA1C yüksekliği, uzun diyabet süresi, nöropati ve retinopati varlığı onikomikozu olan hastalarda anlamlı olarak yüksek bulunmuştur7,9,12,18,20-23. Bizim araştırmamızda onikomikoz infeksiyonu için bağımsız risk faktörleri olarak erkek cinsiyet, 50 yaş ve üzerinde olmak ve nöropati varlığı saptanmıştır. Gupta ve ark. ${ }^{18}$ erkeklerde onikomikoz gelişmini 2,99 kat daha fazla bulmuşlardır. Chang SJ ve ark. 8 yaptığı araştırmada bizim çalışmamızda olduğu gibi fungal infeksiyonlu diyabetik hastalar ve fungal infeksiyon olmayan diyabetli hastalar karşılaştırımış ve bizim araştırmamızla uyumlu olarak erkeklerde ve ileri yaşta anlamlı risk bulmuşlardır. Erkek cinsiyet ve ileri yaş onikomikoz gelişimi açısından en önemli risk faktörü gibi görünmektedir.

Nöropati varlığı hem mantar infeksiyonu gelişimi için hem de diyabetik ayak gelişiminde çok önemlidir. Bu nedenle diyabeti olan ve özellikle nöropatisi olan ileri yaş erkek hastaların ayak ve tırnak bakımı, bu konuyla ilgili eğitimleri özel önem taşır. Diyabeti olan hastalarda fungal infeksiyonların gelişmesinde ileri yaş, erkek cinsiyet, diyabet süresinin uzun olması, retinopati ve nöropatinin önemli risk faktörleri olduğu anlaşılmaktadır. Komplikasyonlar ile korelasyon muhtemelen uzun süreli kontrolsüz seyreden hastalığa işaret etmektedir. Uzun süreli kontrolsüz hastalık mikrosirkülasyonu bozulması ve hücresel immunitenin bozulmasına sebep olarak infeksiyonlara zemin hazırlar. İskemi, nöropati ve hasta savunma sisteminin bozulması hastaların mantar infeksiyonlarına yatkınlığını arttırabilir9.

\section{Sonuç}

Tip 2 diyabet hastalarında erkek ve ileri yaştaki hastalarda, eşlik eden nefropati ve nöropati varlığında fungal infeksiyon gelişme riski artmaktadır. Fungal infeksiyonlar diyabet hastalarında ciddi sonuçlara yol açabileceğinden potansiyel risk taşıyan hastaların mutlaka dermatoloji uzmanlarınca muayene için yönlendirilmesi gerekmektedir. Risk taşıyan hastalar fungal infeksiyonlar açısından özellikle özen gösterilmesi ve hastaların bilgilendirilmesi oluşabilecek komplikasyonların önlenmesinde faydalı olacaktır.

\section{Kaynaklar}

1. Satman I, Yilmaz T, Şengül A, et al: Population-based study of diabetes and risk characteristics in Turkey.Results of the Turkish diabetes epidemiyology study (TURDEP). Diabetes Care 2002;25:1551-6.

2. Terzi $\mathrm{E}$, Peksarı Y: Diabetes mellitusun deri bulguları ve diyabetik ayak. Türkiye Klinikleri J Dermatol 2003;13:50-60.

3. Şensoy G, Gençoğlan G: Tip II diyabetli hastalarda deri bulgularının vücut kitle indeks ve HBA1C ilişkisi. Anatol J Clin Investig 2009;3:213-7.

4. Çiçek $D$, Kandi $B$, Oğuz $S$, ve ark: Diyabetes mellituslu hastalarda gözlenen deri bulguları. F.Ü. Sağ. Bil. Tıp Derg.2010;24:77-80.

5. Hekimsoy Z, Toprak Ö, Bozdağ KE, Aslan S: Diyabetik hastalardaki deri bulguları. Türkiye Klinikleri J Dermatol 2002;12:181-4.

6. Öztürkcan S, Topçu S, Özçelik S, Akıncı S: Diyabetes mellitusda deri bulguları. Türkiye Klinikleri J Dermatol 1993;3:53-6.

7. Foss NT, Polon MH, Takada MH, Foss-Freitas MC, Foss MC: Skin lesions in diabetic patients. Rev Saude Publica 2005;39:677-82.

8. Chang SJ, Hsu SC, Tien KJ, et al: Metabolic syndrome associated with toenail onycomycosis in Taiwanese with diabetes mellitus. Int J Dermatol 2008;47:467-72

9. Dogra S, Kumar B, Bhansali A, Chakrabarty A: Epidemiology of onychomycosis in patients with diabetes mellitus in India. Int J Dermatol 2002;41:647-51.

10. Bristow IR, Spruce MC: Fungal foot infection, cellulitis and diabetes: a review. Diabetic Medicine 2009;26:548-51.

11. Shahzad M, Robaee AA, Hani A, Alzolibani AA, Al Marshood AA, Al Moter B: Skin Manifestations in Diabetic Patients Attending a Diabetic Clinic in the Qassim Region, Saudi Arabia. Med Princ Pract 2011;20:137-41.

12. Romano C, Massai L, Asta F, Signorini M: Prevalence of dermatophytic and nail infections in diabetic patients. Mycoses 2001;44:83-6.

13. Al- Mutairi N, Eassa BI, Al-Rqobah DA: Clinical and mycologic characteristics of onychomycosis in diabetic patients. Acta Dermatovenerol Croat 2010;18:84-91.

14. Schaller M: Candida albicans - Interactions with the mucosa and the immune system. J Dtsch Dermatol Ges 2006;4:328-36.

15. Abu-Elteen $\mathrm{KH}$ : Incidence and distribution of Candida species isolated from human skin in Jordan. Mycoses 1999;42:311-7.

16. Al-Attas SA, Amro SO: Candidal colonization, strain diversity, and antifungal susceptibility among adult diabeticpatients. Ann Saudi Med 2010;30:101-8.

17. Mayser P, Freund V, Budiharja D: Toenail onychomycosis in diabetic patients. Am J Clin Dermatol 2009;10:211-20. 
18. Gupta AK, Konnikov N, MacDonald P, et al: Prevalence and epidemiology of toenail onychomycosis in diabetic subjects a multicentre survey. $\mathrm{Br} J$ Dermatol 1998;139:665-71.

19. Dumont IJ: Diagnosis and prevalence of onychomycosis in diabetic neuropathic patients: an observational study. J Am Podiatr Med Assoc 2009;99:135-9

20. Saunte DM, Holgersen JB, Haedersdal $M$, et al: Prevalence of toe nail onychomycosis in diabetic patients. Acta Derm Venereol 2006;86:425-8.
21. Eckhard M, Lengler A, Liersch J, Bretzel RG, Mayser P: Fungal foot infections in patients with diabetes mellitus-results of two independent investigations. Mycoses 2007;50:14-9.

22. Gulcan A, Gulcan E, Oksuz S, Sahin I, Kaya D: Prevalence of toenail onychomycosis in patients with type 2 diabetes mellitus and evaluation of risk factors. J Am Podiatr Med Assoc 2011;101:49-54.

23. Cathcart S, Cantrell W, Elewski B: Onychomycosis and diabetes. J Eur Acad Dermatol Venereol 2009:23:1119-22. 